\title{
Quantitative determination of five hydroxy acids, precursors of relevant wine aroma compounds in wine and other alcoholic beverages
}

Elisa Gracia-Moreno

Ricardo Lopez 1,*

Email riclopez@unizar.es

Vicente Ferreira 1

1 Laboratorio de Análisis del Aroma y Enología, Departamento de Química Analítica, Facultad de Ciencias, Aragon Institute of Engineering Research (I3A), Universidad de Zaragoza, 50009 Zaragoza, Spain

\section{Abstract}

A method for the quantitative determination of 2-hydroxy-2methylbutanoic (2OH2MB), 2-hydroxy-3-methylbutanoic (2OH3MB), 3hydroxy-3-methylbutanoic (3OH3MB), 2-hydroxy-4-methylpentanoic (2OH4MP) and 3-hydroxybutanoic (3OHB) acids has been optimized, validated and applied to a set of wines and other alcoholic beverages. The analytes were preconcentrated in a solid phase extraction cartridge and derivatized with 2,3,4,5,6-pentafluorobenzyl bromide at room temperature for $30 \mathrm{~min}$, followed by GC-MS analysis. Detection limits were between 0.5 and $29 \mu \mathrm{g} \mathrm{L}^{-1}$, and linearity was maintained up to 3 or $12 \mathrm{mg} \mathrm{L}^{-1}$, depending on the analyte. Recovery values were between 85 and $106 \%$, and reproducibility was better than $12 \% \mathrm{RSD}$ in most cases. The first specific study of these analytes in wine and other alcoholic beverages is herein reported. Concentrations ranged from the method detection limits to $7820,519,8510,3470$ and $2500 \mu \mathrm{g} \mathrm{L^{-1 }}$ for $2 \mathrm{OH} 2 \mathrm{MB}, 2 \mathrm{OH} 3 \mathrm{MB}$, $3 \mathrm{OH} 3 \mathrm{MB}, 2 \mathrm{OH} 4 \mathrm{MP}$ and $3 \mathrm{OHB}$, respectively, which may have relevant 
sensory effects. These products were not found in distillates (except 3OHB) but were all present in beer. $2 \mathrm{OH} 2 \mathrm{MB}, 3 \mathrm{OH} 3 \mathrm{MB}$ and $3 \mathrm{OHB}$ were found in unfermented grape derivatives. Sherry wines had the highest levels of all except for $3 \mathrm{OHB}$.

\section{Keywords}

Hydroxy acid

Wine

Solid phase extraction

Gas chromatography-mass spectrometry

Cheese aroma

Derivatization

Electronic supplementary material

The online version of this article (doi: 10.1007/s00216-015-8959-9) contains supplementary material, which is available to authorized users.

\section{Introduction}

While short chain fatty acids display odours described as cheese, sweat, rancid or acid [1-3], their ethyl esters have pleasant fruity aromas [1,3-5]. As both families of compounds are interrelated due to the esterification/hydrolysis equilibrium [6, 7], relevant aroma changes can take place during ageing if they are initially present at concentration ratios different to that of the corresponding esterification equilibrium [8]. This is certainly the case of ethyl 2-, 3- and 4-methylpentanoate and ethyl cyclohexanecarboxylate which were described by Campo et al. as responsible for powerful strawberry aromas in aged wines and spirits [9, 10]. These compounds are formed by slow esterification with ethanol of the corresponding acids [10] which are naturally present in different wines and alcoholic beverages [11]. This is most surely also the case of other fruity ethyl esters present in wine, such as ethyl 2-hydroxy-4-methylpentanoate and ethyl 2-hydroxy-3-methylbutanoate which were recently identified as powerful strawberry-smelling aroma compounds [10]. The former has been associated with "fresh blackberry aroma" in red wines [12] with reported 
concentrations ranging from $48 \mu \mathrm{g} \mathrm{L}^{-1}$ in blackberry liqueur to $672 \mu \mathrm{g} \mathrm{L}^{-1}$ in one of the aged red wines. While these concentrations are close to but not higher than the perception threshold, the omission of ethyl 2-hydroxy-4methylpentanoate has been detected in many of the omission tests, suggesting an important role in overall wine flavour. Furthermore, an additive effect with ethyl butanoate has been suggested because the omission was more clearly perceived when this included the two esters [12]. The same authors subsequently studied the enantiomeric composition of ethyl 2-hydroxy-4methylpentanoate in a set of 42 red wines and 13 white wines finding mainly the R-enantiomer, with increasing levels of the S-enantiomer in older wines [13]. The sensory study demonstrated a synergic effect of both enantiomers to enhance fruity aromas in wine, in particular "blackberry" and "fresh fruit notes" $[13,14]$.

Ethyl 3-hydroxybutanoate was described in 2009 by Pineau et al. as one of the esters responsible for "redberry" and "blackberry" aromas in red wines. The fact that its concentration is most often under its individual olfactory threshold implies an indirect impact [5], further described as hyper-additive because its addition decreased the threshold of the total aromatic reconstitution by 2.09-fold, although it did not affect the aroma perceived [15]. Other compounds of the same family, such as ethyl 2-hydroxy-2methylbutanoate, have been identified in Tokaji wines [16] and pineapple [17], while ethyl 3-hydroxy-3-methylbutanoate has been found in cashew apple juice [18] and other fruits [19-21].

Some of the corresponding hydroxy acids such as $2 \mathrm{OH} 2 \mathrm{MB}, 2 \mathrm{OH} 3 \mathrm{MB}$ and 2OH4MP have already been identified in wine or wine residues [22-26], although only 2OH4MP has been quantified [24]. These hydroxy acids are also present in other biological matrixes such as honey [27, 28]. Furthermore, 2OH4MP has been found in roasted cocoa [29], fermented soybean [30] and cyanobacteria [31]. 3OHBc is present in grape leaf tissue [32] and has been proposed as a biomarker of grape fungal resistance by Batovska et al. [33]. To the best of our knowledge, no specific studies have so far been carried out to quantify the hydroxy acid potential precursors of any of these important fruity esters in wine or any other product.

The high polarity and low volatility of hydroxy acids make headspace 
techniques difficult to apply. In fact, an SPME method with a DVB/CAR/PDMS fiber found 2OH4MP below the method quantitation limit [25]. Solid-phase extraction (SPE) on polar sorbents is a good option to isolate polar analytes [34], although polar interferences will also be retained. Anionic mixed-mode sorbents would be interesting to take advantage of the acid properties of the analytes, although this kind of sorbent provided low breakthrough volumes in previous work [35]. Pure anionic sorbents were used in the past to isolate acidic compounds present in wine but only as an additional purification step after using a polyvinylpolypyrrolidone column [24].

The polarity of hydroxy acids also determines chromatographic behaviour. While, in general, acids are poorly soluble in apolar columns, the presence of an additional hydroxyl group will provide strong interactions in polar phases, potentially causing tailing effects. Because of this, derivatization is mostly preferred for hydroxy acid analysis [23, 24, 27, 28, 31]. In general, GC-MS has been used to analyse these molecules [23, 24, 27, 28, 31], although GCxGC/TOF-MS has also been used in the analysis of cigarette smoke samples [36].

Among the many derivatizing reagents, 2,3,4,5,6-pentafluorbenzylbromide (PFBBr) can help not just lowering the polarity of the compounds but also increasing their detectability by using the most sensitive and less fragmentation-prone negative chemical ionization (NCI) detection mode [35]. For of all these reasons, a method has been selected combining a fast nonspecific SPE with apolar sorbents, chemical derivatization and further GCNCI-MS analysis in order to provide the first data about the occurrence of the aforementioned hydroxy acids in wine and other alcoholic beverages.

\section{Materials and methods}

\section{Reagents and standards}

The standards of 2-hydroxy-2-methylbutanoic acid (2OH2MB), 2-hydroxy-3methylbutanoic acid (2OH3MB), 2-hydroxy-4-methylpentanoic acid (2OH4MP), 3-hydroxybutanoic acid (3OHMB), 2-hydroxy-2methylpropanoic acid (2OH2MPr) and 2-hydroxy-3,3-dimethylbutanoic acid (2OH33diMB) were purchased from Sigma-Aldrich and 3-hydroxy-3- 
methylbutanoic acid (3OH3MB) from Alfa Aesar, with purity higher than $95 \%$ in all cases. 2,3,4,5,6-Pentafluorobenzyl bromide (PFBBr) and tetrabutylamonium chloride $\left(\mathrm{NBu}_{4} \mathrm{Cl}\right)(>97 \%)$ were also purchased from Aldrich.

The solvents used were: Unisolv quality hexane (Hx), Lichrosolv quality ethanol, Suprasolv quality methanol $(\mathrm{MeOH})$ and dichloromethane (DCM) and diethylie ether, all from Merck. Triethylamine (TEA) $95 \%$ was from Aldrich. A milli-Q purification system (Millipore, Bedford, MA, USA) provided pure water.

Sorbents used were: LiChrolut EN resins pre-packed $(200 \mathrm{mg}, 3 \mathrm{~mL}$ reservoirs) and packed in house (200 $\mathrm{mg}$ in $1 \mathrm{~mL}$ reservoir) from Merck. SPE was performed with the help of a Vac Elut 20 system from Varian. Silica-gel 60 from Merck was used for the purification process.

Standard solutions of the hydroxy acids were prepared directly in ethanol because of their insolubility in apolar solvents.

\section{Wines and alcoholic beverage samples}

A variety of wines (white, rosé, young red, barrel aged red, natural sweet and Sherry) as well as other alcoholic beverages (beer, brandy and whisky) have been analysed. The objective was to test the performance of the method presented in this paper and to have an initial idea of the occurrence of the five hydroxy acids studied in wine and other alcoholic beverages. The whole list of samples analysed is presented in Table S1 of the Electronic Supplementary Material (ESM) with information of their type, brand, origin and grape variety.

\section{SPE method optimization}

The influence of the $\mathrm{pH}$ was studied, comparing two aliquots of the same wine. A red wine aged in wooden barrels for 18 months was spiked with $200 \mu \mathrm{g} \mathrm{L}^{-1}$ of each of the analytes. Two aliquots of $10 \mathrm{~mL}$ each of the spiked wine were analysed. One aliquot was at the natural $\mathrm{pH}$ of the wine (3.5) and the other at $\mathrm{pH} 1.5$ (adjusted with $\mathrm{HCl}, 37 \%$ ). These aliquots were loaded into $200 \mathrm{mg}$ LiChrolut EN cartridges ( $3 \mathrm{~mL}$ reservoir). After drying, elution 
was done with $1 \mathrm{~mL}$ DCM, followed by derivatization and purification through silica gel as explained in the final method.

After that, the influence of several variables on the retention of the analytes was tested, as can be seen in Table 1. A red wine aged in wooden barrels for 18 months spiked with $2 \mathrm{mg} \mathrm{L}^{-1}$ of each of the analytes was used for all the subsequent experiments described in this section. A reference sample was prepared loading $10 \mathrm{~mL}$ of the spiked wine into a pre-packed $200 \mathrm{mg}$ LiChrolut EN bed ( $3 \mathrm{~mL}$ cartridge), washing with $3 \mathrm{~mL}$ of acidified milli-Q water, vacuum-drying and eluting with $1 \mathrm{~mL} \mathrm{DCM}$. The other samples were prepared with $10 \mathrm{~mL}$ aliquots and changing just one variable at a time.

Sorbent bed length: One aliquot was loaded into a 1-mL cartridge containing $200 \mathrm{mg}$ LiChrolut EN (packed in house). Effect of ethanol content: An aliquot was diluted with milli-Q water $(1: 1, v / v)$ prior to loading. Acid washing to clean the extract: An aliquot was processed as the reference but without the washing step. Elution optimization: Two aliquots of the spiked wine were eluted with DCM (reference sample) and DCM/2 \% TEA respectively with fractions of $0.5 \mathrm{~mL}$ volume.

\section{Table 1}

Optimization of the SPE process for hydroxy acid extraction

\begin{tabular}{|c|c|c|c|c|c|}
\hline Experiment & Ref. & $\begin{array}{l}\text { Longer bed } \\
\text { length }\end{array}$ & $\begin{array}{l}\text { Diluted } \\
\text { wine }\end{array}$ & $\begin{array}{l}\text { Without } \\
\text { washing }\end{array}$ & $\begin{array}{l}\text { TEA }(2 \%) \\
\text { elution }\end{array}$ \\
\hline $\begin{array}{l}\text { Sorbent bed } \\
\text { (mg) }\end{array}$ & 200 & 200 & 200 & 200 & 200 \\
\hline $\begin{array}{l}\text { Cartridge } \\
\text { volume }(\mathrm{mL})\end{array}$ & 3 & 1 & 3 & 3 & 3 \\
\hline Wine $(\mathrm{mL})$ & 10 & 10 & $10: 10$ & 10 & 10 \\
\hline $\begin{array}{l}\text { Acid washing } \\
\text { step }(\mathrm{mL})\end{array}$ & 3 & 3 & 3 & - & 3 \\
\hline Elution (1 mL) & DCM & $\mathrm{DCM}$ & DCM & DCM & $\begin{array}{l}\text { TEA }(2 \%) / \\
\text { DCM }^{\mathrm{a}} \%\end{array}$ \\
\hline
\end{tabular}

The recovery of analyte in the SPE process was evaluated after its 
optimization comparing two extracts. Two aliquots of $10 \mathrm{~mL}$ each of a red wine were used. One of the aliquots was spiked with $75 \mu \mathrm{L}$ of a solution containing $450 \mathrm{mg} \mathrm{L}^{-1}$ of the analytes and $25 \mu \mathrm{L}$ of a solution containing $1200 \mathrm{mg} \mathrm{L}^{-1}$ of the internal standards (2OH2MPr acid and 2OH33diMB acid), both in ethanol, prior to the analysis with the final method, while the other aliquot was processed without being spiked. The extract of the unspiked sample was spiked with the same amount of the analytes and internal standards. To avoid any difference produced by the ethanol added to the spiked extract, the same amount of ethanol $(100 \mu \mathrm{L})$ was added to the other extract. The same conditions were used to derivatize and analyse the two extracts.

\section{Derivatization reaction}

The derivatization procedure used in this study is based on a procedure optimized for branched acids in a previous work [35]. That is, to say, $20 \mu \mathrm{L}$ of pure 2,3,4,5,6-pentafluorobenzyl bromide (PFBBr) and $500 \mu \mathrm{L}$ of a solution of tetrabutylamonium chloride $0.1 \mathrm{M}$ at pH 6 were added to $500 \mu \mathrm{L}$ of DCM containing the analytes. After 30 min of stirring at room temperature, the reaction is stopped with $\mathrm{HCl}(37 \%)$. The extract is purified through a 200-mg silica gel bed and, after a washing step with $1.5 \mathrm{~mL}$ of hexane, is eluted with $1 \mathrm{~mL}$ of $20 \%$ of diethyl ether in hexane. Firstly, the aforementioned derivatization and further purification were applied to dichloromethane solutions $(50 \mathrm{mg} / \mathrm{L})$ of the standards to characterize the derivatized compounds. They were injected in a GC-MS with a DB-WAX column, and their linear retention indexes were determined (Table 2). Their spectra, both in EI and in NCI mode, are shown in the ESM of this paper.

\section{Table 2}

Linear retention indices for the hydroxy acids studied and their corresponding PFB esters in a DB-WAX column

\begin{tabular}{|c|c|c|c|c|c|c|c|}
\hline \multirow{2}{*}{ Compound } & \multirow{2}{*}{$\begin{array}{c}\text { CAS } \\
\text { number }\end{array}$} & \multirow{2}{*}{ pKa } & \multirow{2}{*}{$\log P$} & \multicolumn{2}{|r|}{ Mw } & \multicolumn{2}{|c|}{$\begin{array}{l}\text { LRI (DB- } \\
\text { WAX) }\end{array}$} \\
\hline & & & & Acid & $\begin{array}{l}\text { PFB- } \\
\text { ester }\end{array}$ & Acid & $\begin{array}{l}\text { PFB- } \\
\text { ester }\end{array}$ \\
\hline $2 \mathrm{OH} 2 \mathrm{MPr}^{\mathrm{a}}$ & $594-61-6$ & 4.01 & -0.44 & 104 & 284 & 2047 & 1878 \\
\hline
\end{tabular}




\begin{tabular}{|c|c|c|c|c|c|c|c|}
\hline $2 \mathrm{OH} 2 \mathrm{MB}$ & $3739-30-8$ & 4.05 & 0.07 & 118 & 298 & 2093 & 1920 \\
\hline $3 \mathrm{OH} 3 \mathrm{MB}$ & $625-08-1$ & 4.38 & -0.35 & 118 & 298 & 2090 & 2027 \\
\hline $2 \mathrm{OH} 33 \mathrm{diMB}^{\mathrm{b}}$ & $4026-20-4$ & 3.91 & 0.42 & 132 & 312 & 2278 & 2033 \\
\hline $2 \mathrm{OH} 3 \mathrm{MB}$ & $4026-18-0$ & 3.87 & 0.01 & 118 & 298 & 2259 & 2034 \\
\hline 2OH4MP & $498-36-2$ & 3.86 & 0.52 & 132 & 312 & 2416 & 2082 \\
\hline $3 \mathrm{OHBc}$ & $300-85-6$ & 4.36 & -0.76 & 104 & 284 & 2226 & 2087 \\
\hline \multicolumn{8}{|c|}{ a Internal standard (IS-1) } \\
\hline
\end{tabular}

The purification after the reaction had to be optimized. For this purpose, a DCM solution of the standards was derivatized as already explained. Then, the purification through the silica was done with several fractions of hexane (1 mL each) containing increasing amounts of ether (20, 40 and $60 \%)$.

\section{Chromatographic conditions}

A CP-3800 chromatograph coupled to a Saturn 2200 ion trap massspectrometric detection system from Varian (Sunnyvale, CA, USA) was used during the development of the method. The capillary column used was a DBWAX ETR (J\&W Scientific, Folsom, CA, USA) $(60 \mathrm{~m}, 0.25 \mathrm{~mm}, 0.25 \mu \mathrm{m})$ preceded by a $3 \mathrm{~m} \times 0.25 \mathrm{~mm}$ uncoated (deactivated, intermediate polarity) pre-column from Supelco (Bellefonte, USA). Helium was the carrier gas at a flow rate of $1 \mathrm{~mL} \mathrm{~min}^{-1}$. The oven temperature programme was $4 \mathrm{~min}$ at $40{ }^{\circ} \mathrm{C}$, increased by $10^{\circ} \mathrm{C} \min ^{-1}$ up to $150{ }^{\circ} \mathrm{C}$, with a second ramp at $4{ }^{\circ} \mathrm{C} \min ^{-1}$ up to $190{ }^{\circ} \mathrm{C}$ and a third at $2{ }^{\circ} \mathrm{C} \min ^{-1}$ up to $220^{\circ} \mathrm{C}$ and finally held at this temperature for $20 \mathrm{~min}$. The MS-parameters were: MS transfer line $220^{\circ} \mathrm{C}$ and ionization chamber temperature $170{ }^{\circ} \mathrm{C}$. Two microliters of the extract were injected in splitless mode for 2 min with a pulse pressure of 30 psi.

The analysis of the extracts in the final method was done in an Agilent 7890A GC coupled to a $5975 \mathrm{MS}$ in NCI mode. In this case, the column was a CPWAX $52 \mathrm{CB}(25 \mathrm{~m}, 0.15 \mathrm{~mm}, 0.25 \mu \mathrm{m})$ from Varian preceded by a $3 \mathrm{~m} \times$ $0.25 \mathrm{~mm}$ uncoated (deactivated, intermediate polarity) pre-column from 
Supelco (Bellefonte, USA). Two microliters of sample were automatically injected at $250{ }^{\circ} \mathrm{C}$ for $4.5 \mathrm{~min}$ of splitless time with helium at $45 \mathrm{~cm} \mathrm{~s}^{-1}$ as the carrier gas and a pulse pressure of $59 \mathrm{psi}$ during the splitless time. The oven was programed as follows: $40^{\circ} \mathrm{C}$ during $5 \mathrm{~min}$, ramp of $10{ }^{\circ} \mathrm{C} \mathrm{min}^{-1}$ up to $115^{\circ} \mathrm{C}$ and a final ramp of $4{ }^{\circ} \mathrm{C} \mathrm{min}^{-1}$ up to $230^{\circ} \mathrm{C}$. This temperature was held for $20 \mathrm{~min}$. The spectrometer operated in negative chemical ionization (NCI) with methane as ionization gas ( 3 bars of pressure). The temperature of the ion source and quadrupole were set at $150{ }^{\circ} \mathrm{C}$ and transferline temperature was $150^{\circ} \mathrm{C}$. The acquisition of mass spectra was done after 10 min solvent delay, scanning from 40 to $300 \mathrm{amu}$.

\section{Final method}

For the extraction of the analytes, conditioning of $200 \mathrm{mg}$ of LiChrolut sorbents ( $1 \mathrm{~mL}$ cartridge, in house packed) is done with $4 \mathrm{~mL}$ of DCM, $4 \mathrm{~mL}$ of $\mathrm{MeOH}$ and $4 \mathrm{~mL}$ of hydroalcoholic solution (12\% ethanol). Highly alcoholic beverages, such as whisky and brandy, are diluted prior to the analysis to $12 \%$ content of ethanol. A volume of $10 \mathrm{ml}$ of wine spiked with $2 \mathrm{OH} 3 \mathrm{MPr}$ (IS-1) and 2OH33diMB (IS-2) to obtain a concentration of 3.4 and $2.7 \mathrm{mg} \mathrm{L}^{-1}$, respectively, is loaded into the sorbents at the natural $\mathrm{pH}$ of wine with the help of a vacuum device. Then, the sorbents are vacuum-dried and eluted with $1 \mathrm{~mL}$ of DCM with $2 \%$ of TEA. The extracts are recovered in $2 \mathrm{~mL}$ glass vials.

The derivatization procedure used is the same as that described in [35], whereas the purification requires the use of more polar solvents. The addition of $20 \mu \mathrm{L}$ pure PFBBr and $500 \mu \mathrm{L} \mathrm{NBu}_{4} \mathrm{Cl} 0.1 \mathrm{M}$ in buffered solution ( $\mathrm{pH} 6.0$ ) to each of the extracts is followed by $30 \mathrm{~min}$ of stirring at room temperature. The reaction ends by adding $\mathrm{HCl}(37 \%)$. After discarding the aqueous phase, the organic phase is washed with acidified milli-Q water and dried with $\mathrm{Na}_{2} \mathrm{SO}_{4}$. The purification is done in cartridges $(1 \mathrm{~mL})$ containing $200 \mathrm{mg}$ bed of silica-gel 60 . After a washing step with $1.5 \mathrm{~mL}$ of hexane, the analytes are eluted with $1 \mathrm{~mL}$ of hexane/ $60 \%$ diethyl ether $(v / v)$.

Analysis: $2 \mu \mathrm{L}$ of the extract is injected in splitless mode in a GC-MS and analysed in NCI mode as described in the previous section. 


\section{Method linearity and reproducibility}

The external calibration method with internal standard was used to assess the linearity and to calculate the concentrations. The linearity was studied spiking several wines with known amounts of the standards solutions (prepared in pure ethanol) up to $10 \mathrm{mg} \mathrm{L}^{-1}$ (six points per linearity curve). The relative area obtained for the unspiked wine was subtracted to each of the points in the curve. The concentrations were calculated by the direct interpolation in the calibration curve of the peak area of each compound divided by the corresponding internal standard peak area. Calibration curves linearity was confirmed by evaluating residual distribution, and no weighing factors were necessary. The slopes of the calibration curves obtained from different types of wines and alcoholic beverages were compared with an F-test (95\% level of confidence) to detect matrix effects. The reproducibility and recovery of signal were measured analysing three replicates of two wines spiked with $3 \mathrm{mg} \mathrm{L}^{-1}$ of each of the analytes: a white (Albada, DO Calatayud) and a rosé (Homenaje, DO Navarra).

\section{Results and discussion}

\section{Method optimization}

The sorbent (200 mg LiChrolut EN) and the volume of wine $(10 \mathrm{~mL})$ were set based on previous experience [34, 37]. No significant improvement was found by lowering the $\mathrm{pH}$, and therefore, the $\mathrm{pH}$ of the wine was not changed in further studies. By contrast, and as expected, the length of the SPE bed had a marked influence, as shown in Fig. S3 of the ESM. This occurs because the chromatographic retention factors for these polar compounds are very small, and hence, breakthrough volumes are easily reached so that the bed length becomes critical. A longer sorbent bed with the same amount of sorbent provided much higher retentions (50-110\% increment) for the four hydroxy acids. In consequence, it was decided to pack $200 \mathrm{mg}$ of the sorbents in $1 \mathrm{~mL}$ cartridges.

Sample dilution with water (1:1) improved retention of $2 \mathrm{OH} 2 \mathrm{MB}$, suggesting that this compound has the lowest breakthrough volume. Similarly, washing the cartridge with acid water reduced recoveries of all analytes, suggesting that even in acid water, breakthrough volumes are very small which does not 
leave room for a cleanup. A 2-mL volume of DCM was required for the elution, but this volume could be reduced to $1 \mathrm{~mL}$ by adding $2 \%$

triethylamine (TEA). Summarizing, the optimum conditions for the extraction process included the use of $200 \mathrm{mg}$ of sorbent in a 1-mL volume cartridge without dilution of the wine or washing step and elution with $1 \mathrm{~mL}$ of DCM/ $2 \%$ TEA.

Even under such conditions, recoveries were very low for some of the analytes, as shown in Fig. 1 and as expected, were inversely related to the polarity of the hydroxy acids. We tried to correct the potential bias and imprecision caused by these low recoveries by using two internal standards (IS) similar in polarity and retention to each one of the analytes displaying extreme behaviour, as shown in Fig. 1 . 2-hydroxy-2-methyl propanoic $(2 \mathrm{OH} 2 \mathrm{MPr})$ is very close in properties and retention to the most polar 3OHB, while 2-hydroxy-3,3-dimethylbutanoic (2OH33diMB) is very similar to the least polar $2 \mathrm{OH} 4 \mathrm{MP}$.

\section{Fig. 1}

Recovery (\%) of the hydroxy acids through the SPE process. The two IS are presented in a different colour. The numbers above the bars represent the polarity ( $\log \mathrm{P}$ values)

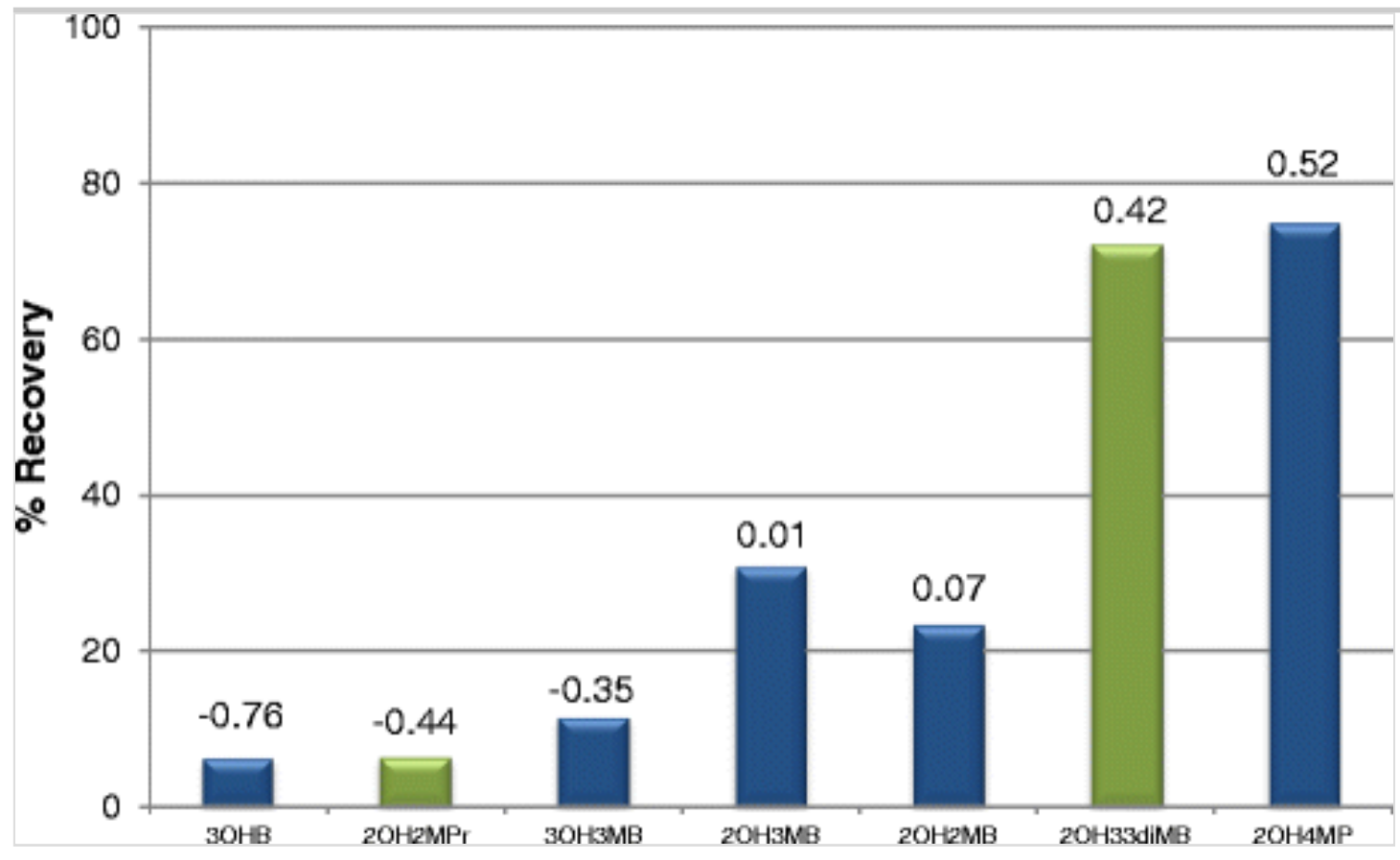

The polar nature of the analytes and their small size make convenient the use 
of a derivatization process to improve their chromatographic and detectability properties. Derivatization with PFBBr is suitable for anionic compounds, which can undergo nucleofilic substitution [35, 38]. In particular, this reaction has been recently optimized for a group of branched chain fatty acids [35]. The hydroxy acids studied in the present work are very similar to those branched acids; in consequence, a similar behaviour towards PFBBr can be expected. Thus, the derivatization reaction conditions developed for branched acids in [35] were tested and found to be appropriate for hydroxy acids. However, the silica cleanup step had to be modified by using diethyl ether instead of toluene to account for the higher polarity of these analytes because toluene' strength was not enough to remove the hydroxy acids from the silicagel. The less polar PFB-hydroxy esters start eluting with just $20 \%$ of diethyl ether in hexane, whereas the most polar one (PFB-3OHBc) needs $40 \%$ diethyl ether to start eluting and $60 \%$ to complete its full elution. Therefore, $60 \%$ of diethyl ether is used in the silica cleanup.

Derivatized analytes can be quantified in electron impact (EI) mode when their fragmentation is selective enough. The use of highly halogenated reagents together with negative chemical ionization (NCI) allows increasing the sensitivity of the method. The PFB esters obtained in this case allowed the use of NCI due to their high affinity for negative electrons and their capacity to stabilize a negative charge. EI and NCI mass spectra of the PFB-esters obtained are given in the ESM. Linear retention indices determined in a DBWAX column are presented in Table 2. In EI mode, the fragment with highest abundance $(\mathrm{m} / \mathrm{z} 181)$ corresponded to the derivatizing reagent. This fragment presented many interfering compounds, which could not be resolved by adjusting the chromatographic conditions. Hence, more specific and selective but less sensitive fragments were used to quantify with this ion source (Table 3 ). Unfortunately, $3 \mathrm{OH} 3 \mathrm{MB}$ was present at such low levels in the extracts that the sensitivity provided by EI did not suffice since its mass spectrum lacks characteristic ions. 3OHB concentrations were higher, but again, the poor fragmentation provided by EI mode did not allow its detection. By contrast, in the case of NCI, fragmentation is limited to the cleavage of the ester bond and the main ion corresponds to the deprotonated original hydroxy acid (see ESM) because of its ability to stabilize the negative charge [35]. A typical chromatogram (Oloroso wine sample) obtained by both ionization modes can be seen in Figs. 2 (EI mode) and 3 (NCI mode). Both figures 
show the ionic chromatograms of the PFB esters with the fragments used to quantify each of the analytes and the internal standards.

\section{Table 3}

Fragments, IS and ionization mode used to quantify the analytes and figures of merit of the analysis

\begin{tabular}{|c|c|c|c|c|c|c|c|c|}
\hline \multirow{2}{*}{ Compound } & \multicolumn{2}{|c|}{$m / z$} & \multirow{2}{*}{ IS } & \multirow{2}{*}{$\begin{array}{c}\text { LOD } \\
(\mu \mathrm{g} / \mathrm{L})\end{array}$} & \multirow{2}{*}{$\begin{array}{c}\text { LOQ } \\
(\mu \mathrm{g} / \mathrm{L})\end{array}$} & \multirow{2}{*}{$\begin{array}{c}\text { Linear } \\
\text { range } \\
(\mu \mathrm{g} / \mathrm{L})\end{array}$} & \multicolumn{2}{|c|}{$\begin{array}{l}\text { Recovery (\%) } \\
\pm \operatorname{RSD}(\%)\end{array}$} \\
\hline & EI & NCI & & & & & White & Rosé \\
\hline $\begin{array}{l}\text { PFB- } \\
\text { 2OH2MPra }\end{array}$ & 59 & 103 & - & - & - & - & - & - \\
\hline $\begin{array}{l}\text { PFB- } \\
2 \mathrm{OH} 2 \mathrm{MB}^{\mathrm{d}}\end{array}$ & 73 & 117 & $\begin{array}{l}\text { IS- } \\
1\end{array}$ & 29 & 97 & $97-9500$ & $\begin{array}{l}103 \pm \\
12\end{array}$ & $\begin{array}{l}91 \pm \\
10\end{array}$ \\
\hline $\begin{array}{l}\text { PFB- } \\
3 \mathrm{OH} 3 \mathrm{MB}^{\mathrm{e}}\end{array}$ & 283 & 117 & $\begin{array}{l}\text { IS- } \\
1\end{array}$ & 0.5 & 1.7 & $1.7-3900$ & $3^{104 \pm}$ & $89 \pm 8$ \\
\hline $\begin{array}{l}\text { PFB- } \\
2 \mathrm{OH} 33 \mathrm{diMB}^{\mathrm{b}}\end{array}$ & 236 & 131 & - & - & - & - & - & - \\
\hline $\begin{array}{l}\text { PFB- } \\
2 \mathrm{OH} 3 \mathrm{MB}^{\mathrm{d}}\end{array}$ & 73 & 117 & $\begin{array}{l}\text { IS- } \\
1\end{array}$ & 8.6 & 29 & $29-4700$ & $\begin{array}{l}103 \pm \\
6\end{array}$ & $\begin{array}{l}85 \pm \\
17\end{array}$ \\
\hline $\begin{array}{l}\text { PFB- } \\
2 \mathrm{OH} 4 \mathrm{MP}^{\mathrm{d}}\end{array}$ & 69 & 131 & $\begin{array}{l}\text { IS- } \\
2\end{array}$ & 7.2 & 24 & $24-3600$ & $\begin{array}{l}106 \pm \\
5\end{array}$ & $\begin{array}{l}101 \pm \\
3\end{array}$ \\
\hline $\mathrm{PFB}-3 \mathrm{OHBc} \mathrm{c}^{\mathrm{e}}$ & 87 & 103 & $\begin{array}{l}\text { IS- } \\
1\end{array}$ & 3.6 & 12 & $12-12500$ & $\begin{array}{l}101 \pm \\
4\end{array}$ & $\begin{array}{l}102 \pm \\
5\end{array}$ \\
\hline \multicolumn{9}{|c|}{ anternal standard (IS-1) } \\
\hline \multicolumn{9}{|c|}{ b Internal standard (IS-2) } \\
\hline \multicolumn{9}{|c|}{$\begin{array}{l}{ }^{\mathrm{c}} \text { The number of replicates for the recovery of signal study and the reproducibility } \\
\text { was } 3\end{array}$} \\
\hline \multicolumn{9}{|c|}{${ }^{d}$ Figures of merit correspond to the EI detection method } \\
\hline
\end{tabular}

\section{Fig. 2}

SPE//GC-MS-EI chromatogram (DB-WAX ETR) of an Oloroso wine: $7090 \mathrm{mg} \mathrm{L}^{-1} 2 \mathrm{OH} 2 \mathrm{MB}(\mathrm{m} / \mathrm{z} 73$, red $), 2410 \mathrm{mg} \mathrm{L}^{-1} 2 \mathrm{OH} 3 \mathrm{MB}(\mathrm{m} / \mathrm{z} 73$, red $)$, $1180 \mathrm{mg} \mathrm{L}^{-1}$ 2OH4MP ( $\mathrm{m} / \mathrm{z} 69$, dark blue). The peaks signaled by the arrows 
correspond to the derivatized PFB-esters of the analytes and internal standards

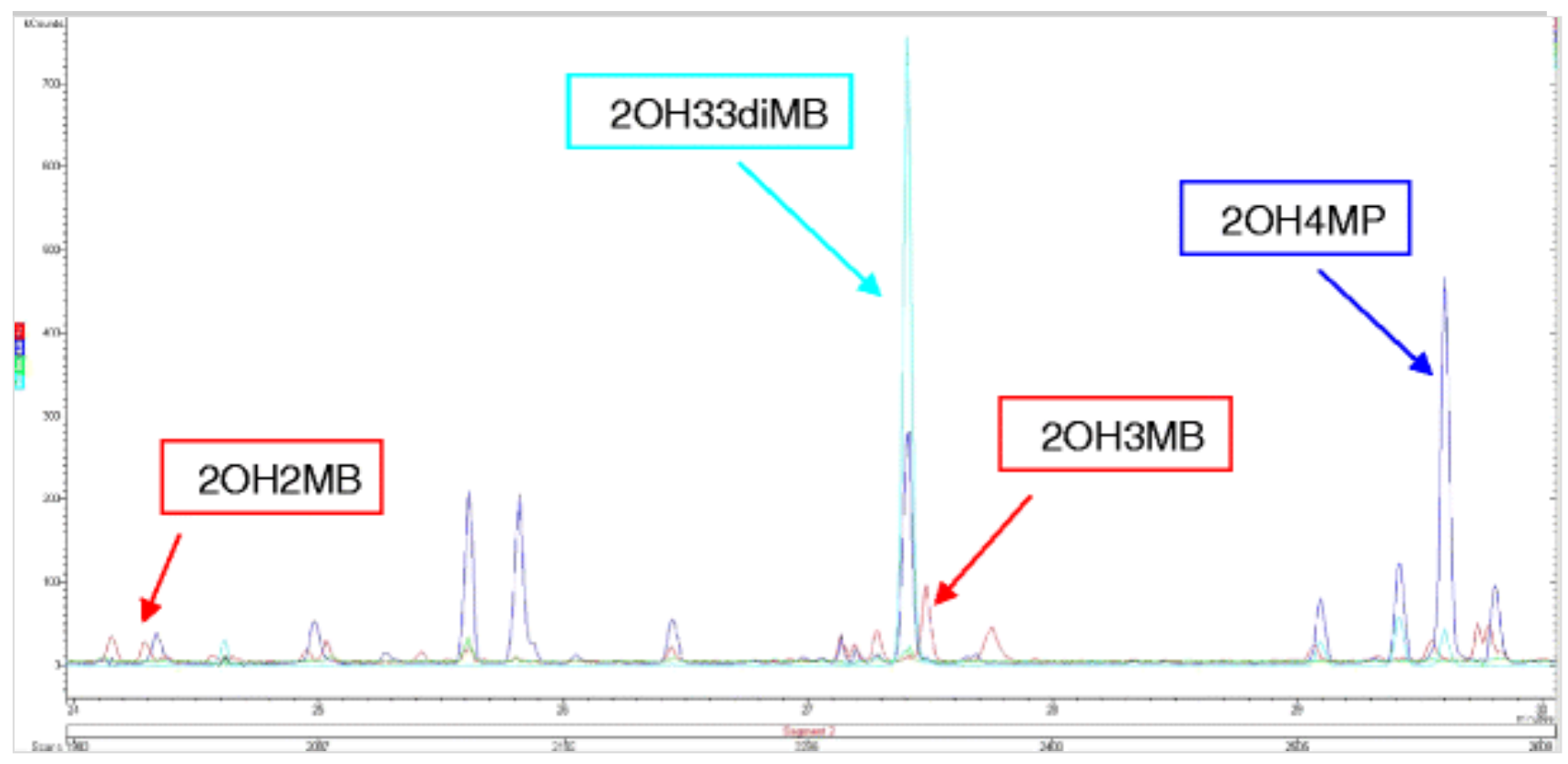

Fig. 3

SPE//GC-MS-NCI chromatogram (CP-WAX $52 \mathrm{CB}$ ) of an Oloroso wine: $7090 \mathrm{mg} \mathrm{L}^{-1} 2 \mathrm{OH} 2 \mathrm{MB}\left(\mathrm{m} / z\right.$ 117, blue), $519 \mathrm{mg} \mathrm{L}^{-1} 3 \mathrm{OH} 3 \mathrm{MB}(\mathrm{m} / z$ 117, blue $)$, $2410 \mathrm{mg} \mathrm{L}^{-1}$ 2OH3MB (m/z 117, blue), $1180 \mathrm{mg} \mathrm{L}^{-1}$ 2OH4MP $(\mathrm{m} / z \mathrm{131}$, red $)$, $863 \mathrm{mg} \mathrm{L} \mathrm{L}^{-1} 3 \mathrm{OHB}(\mathrm{m} / \mathrm{z} 103$, black $)$. The peaks signaled by the arrows correspond to the derivatized PFB-esters of the analytes and internal standards

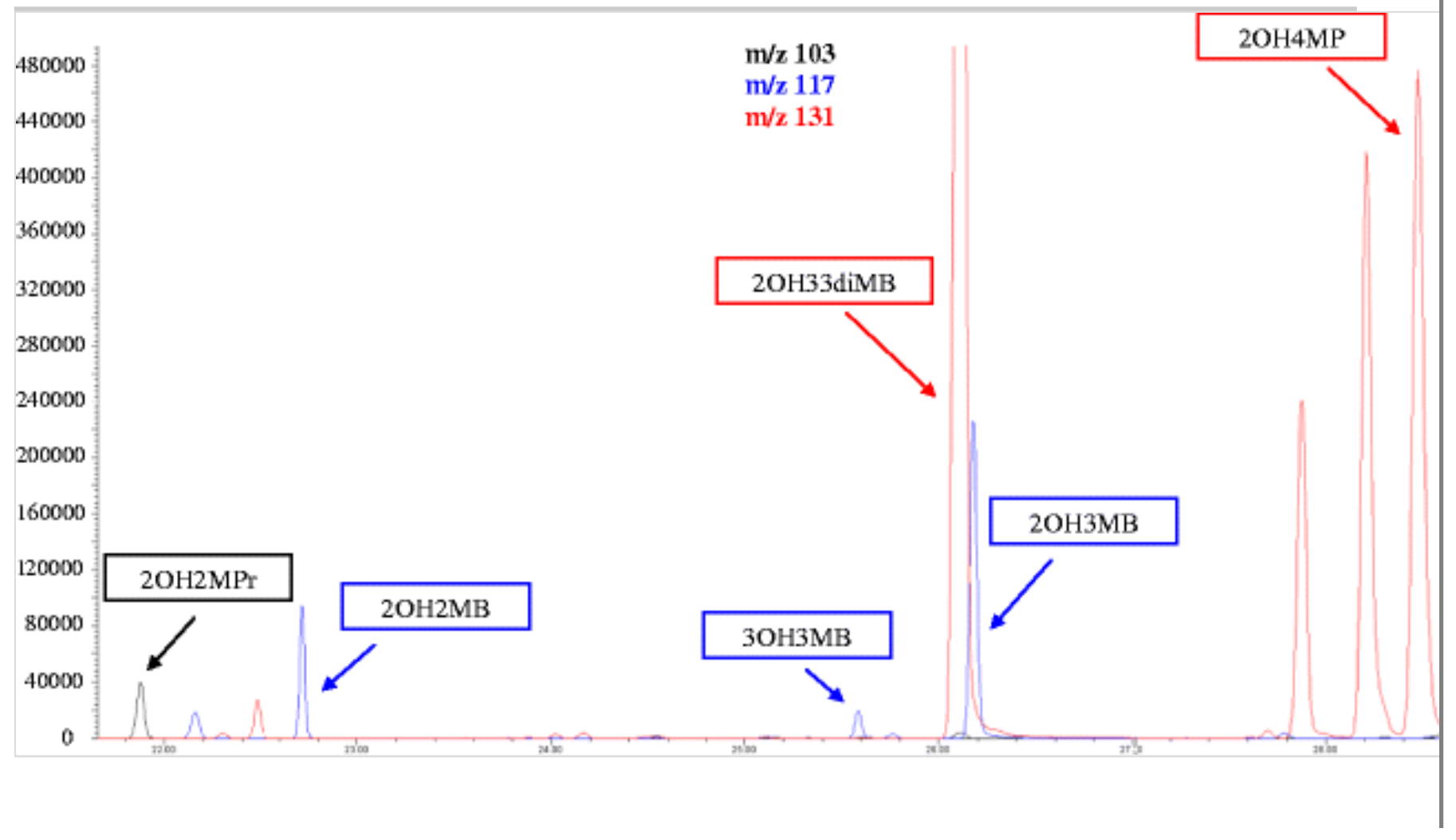


For each of the studied analytes, the internal standard providing the most accurate results was chosen for calibration. In all cases, very good signal recoveries with reasonable RSD were obtained, as shown in Table 3 , in spite of the low extraction recoveries of analyte mass obtained in the SPE process, as was mentioned previously. This is remarkable because it shows that the use of a good internal standard can counterweight low recoveries of analyte during extraction.

Limits of detection (LODs) were estimated by the analysis of real samples and the figures obtained correspond to the concentration at which the signalto-noise ratio becomes 3 . The detection limits ranged between 0.5 and $29 \mu \mathrm{g} \mathrm{L}^{-1}$, as seen in Table 3 . In a similar fashion, limits of quantitation (LOQs) were calculated as the concentration at which the signal-to-noise ratio becomes 10 (Table 3 ). The method proved to be linear for all the analytes from the LOQs up to a few $\mathrm{mg} \mathrm{L}^{-1}$. Reproducibility was satisfactory (RSD equal to or better than $10 \%$ ) in nearly all cases, particularly taking into account that the method includes several steps. In the case of $2 \mathrm{OH} 3 \mathrm{MB}, \mathrm{a}$ high standard deviation was observed in the rosé wine. Matrix effects were studied through a comparison of the slopes obtained in the calibration for each analyte. Only $3 \mathrm{OH} 3 \mathrm{MB}$ was free of such an effect at $95 \%$ confidence. For the other four hydroxy acids investigated, it is necessary to do a calibration curve for each type of beverage analysed: white, red, distilled beverages and so on. Unfortunately, the presence of matrix effects is quite common in complex matrices such as wine and in particular when derivatization is used in the process $[11,39]$.

\section{Occurrence in different wines and alcoholic beverages}

The concentrations of the analytes are presented in Table 4 . The great differences among the ranges of the analyte concentrations give an idea of their different biological origins. Three hydroxy acids have been detected in most of the samples analysed (2OH2MB, 2OH4MP and $3 \mathrm{OHBc})$, whereas $3 \mathrm{OH} 3 \mathrm{MB}$ was detected only in a few of them. $2 \mathrm{OH} 2 \mathrm{MB}$ and $2 \mathrm{OH} 3 \mathrm{MB}$ have higher ranges of concentration due to the large values found for these two compounds in some Sherry wines, up to 7 or $8 \mathrm{mg} \mathrm{L}^{-1}$. 2OH4MP and $3 \mathrm{OHBc}$ have concentrations lower than $4 \mathrm{mg} \mathrm{L}^{-1}$ and $3 \mathrm{OH} 3 \mathrm{MB}$ lower than $600 \mu \mathrm{g} \mathrm{L}$ -1 . The concentrations of $2 \mathrm{OH} 4 \mathrm{MP}$ reported in wine by Drawert et al. were 
$<10 \mathrm{mg} \mathrm{L}^{-1}$ [24], whereas in a by-product of a Chinese liquor the concentrations were larger, up to $60 \mathrm{mg} \mathrm{L}^{-1}$ [40].

\section{Table 4}

Concentrations of the hydroxy acids $(\mu \mathrm{g} / \mathrm{L})$ studied

\begin{tabular}{|c|c|c|c|c|c|c|c|}
\hline $\begin{array}{c}\text { Sample } \\
\text { type }\end{array}$ & Year & $\begin{array}{c}\% \\
\text { EtOH }\end{array}$ & $2 \mathrm{OH} 2 \mathrm{MB}$ & ЗОНЗМВ & $20 H 3 \mathrm{MB}$ & 2ОH4MP & $30 H$ \\
\hline $\begin{array}{l}\text { Young } \\
\text { white } 1\end{array}$ & 2012 & 14.0 & 1940 & $<\mathrm{DL}$ & $<\mathrm{DL}$ & 320 & 775 \\
\hline $\begin{array}{l}\text { Young } \\
\text { white } 2\end{array}$ & 2012 & 13.5 & 198 & $<\mathrm{DL}$ & 214 & 876 & 726 \\
\hline Rosé 1 & 2012 & 13.5 & 408 & $<\mathrm{DL}$ & $<\mathrm{DL}$ & 525 & $112 C$ \\
\hline Rosé 2 & 2012 & 13.0 & $<\mathrm{DL}$ & $<\mathrm{DL}$ & $<\mathrm{DL}$ & 265 & 931 \\
\hline Rosé 3 & 2012 & 13.5 & $<\mathrm{DL}$ & $<\mathrm{DL}$ & $<\mathrm{DL}$ & 270 & 937 \\
\hline $\begin{array}{l}\text { Young red } \\
1\end{array}$ & 2011 & 13.5 & 1070 & $<\mathrm{DL}$ & 191 & 1370 & $210 C$ \\
\hline $\begin{array}{l}\text { Young red } \\
\text { Po }\end{array}$ & 2012 & 13.5 & 1160 & $<\mathrm{DL}$ & 1580 & 1750 & $122 c$ \\
\hline${ }_{3}^{\text {Young red }}$ & 2012 & 13.0 & $<\mathrm{DL}$ & $<\mathrm{DL}$ & 899 & 985 & $212 c$ \\
\hline $\begin{array}{l}\text { Barrel } \\
\text { aged red } 1\end{array}$ & 2008 & 14.1 & 211 & 13 & 397 & 1060 & $250 C$ \\
\hline $\begin{array}{l}\text { Barrel } \\
\text { aged red } 2\end{array}$ & 2007 & 13.5 & 3020 & 12 & 1411 & 1110 & $145 C$ \\
\hline $\begin{array}{l}\text { Barrel } \\
\text { aged red } 3\end{array}$ & 2008 & 13.5 & 1250 & $<\mathrm{DL}$ & $<\mathrm{DL}$ & 1050 & $222 c$ \\
\hline $\begin{array}{l}\text { Barrel } \\
\text { aged red } 4\end{array}$ & 2010 & 14.5 & 1150 & $<\mathrm{DL}$ & $<\mathrm{DL}$ & 911 & $236 c$ \\
\hline $\begin{array}{l}\text { Grape } \\
\text { must } \\
\text { alcoholic } \\
\text { bv } 1\end{array}$ & 2012 & 15.2 & 1740 & 7.9 & $<\mathrm{DL}$ & $<\mathrm{DL}$ & $<\mathrm{DI}$ \\
\hline $\begin{array}{l}\text { Grape } \\
\text { must } \\
\text { alcoholic } \\
\text { bv } 2\end{array}$ & 2012 & 15.5 & 754 & 294 & $<\mathrm{DL}$ & $<\mathrm{DL}$ & 428 \\
\hline
\end{tabular}

Oloroso 


\begin{tabular}{|c|c|c|c|c|c|c|c|}
\hline Sherry & $4^{\mathrm{a}}$ & 18.0 & 7090 & 519 & 2410 & 1180 & 863 \\
\hline $\begin{array}{l}\text { Manzanilla } \\
\text { Sherry }\end{array}$ & $3^{\mathrm{a}}$ & 15.0 & 7820 & $<\mathrm{DL}$ & 8510 & 3470 & 2110 \\
\hline $\begin{array}{l}\text { Pedro } \\
\text { Ximenez } \\
\text { Sherry }\end{array}$ & $2^{\mathrm{a}}$ & 15.0 & 611 & $<\mathrm{DL}$ & 525 & 803 & 782 \\
\hline Beer & - & 5.2 & 83 & 129 & 205 & 266 & 194 \\
\hline $\begin{array}{l}\text { Imperial } \\
\text { Brandy }\end{array}$ & $5^{\mathrm{a}}$ & 38.0 & $<\mathrm{DL}$ & $<\mathrm{DL}$ & $<\mathrm{DL}$ & $<\mathrm{DL}$ & 300 \\
\hline $\begin{array}{l}\text { Pure Malt } \\
\text { Scotch } \\
\text { Whisky }\end{array}$ & $10^{\mathrm{a}}$ & 40.0 & $<\mathrm{DL}$ & $<\mathrm{DL}$ & $<\mathrm{DL}$ & $<\mathrm{DL}$ & 327 \\
\hline
\end{tabular}

\section{$D L$ detection limit}

${ }^{a}$ Sample with no attributable vintage date on the bottle. Instead, the aging period (yec is indicated

The low presence of hydroxy acids in rosé wines is notable. Neither $3 \mathrm{OH} 3 \mathrm{MB}$ nor $2 \mathrm{OH} 3 \mathrm{MB}$ was detected in this type of wines, whereas $2 \mathrm{OH} 2 \mathrm{MB}$ was present in only one of the rosé samples analysed. In general, red wines had larger amounts of the five hydroxy acids studied than rosé and white wines. This could be the result of the different types of vinification process.

2OH3MB and 2OH4MP were not detected in either of the two-grape mustderived alcoholic beverages analysed, strongly suggesting an exclusive fermentative origin for both compounds. The ability of some bacteria genus to transform leucine into 2OH4MP and valine into $2 \mathrm{OH} 3 \mathrm{MB}$ has already been reported in the literature [41-43]. Besides, the concentrations of $2 \mathrm{OH} 4 \mathrm{MP}$ and its ethyl ester in Chinese liquor showed significant differences, depending on the yeast used [40]. By contrast, the relatively high levels of $2 \mathrm{OH} 2 \mathrm{MB}$ and $3 \mathrm{OH} 3 \mathrm{MB}$ in this kind of unfermented products suggest that these compounds are originated in grapes.

With the exception of $3 \mathrm{OHBc}$, the highest concentrations of the hydroxy acids studied were found in the Sherry wines. The differences in concentration with respect to other types of wine are particularly significant in the case of $2 \mathrm{OH} 2 \mathrm{MB}$ and 2OH3MB. In Sherry wines, the concentrations are between 2 
and 40 times higher than in the other types of wine. This might be related with the special vinification and ageing processes undergone by Sherry wines. Further details of the comparison of samples and their oenological meaning can be found in [44].

As for the other alcoholic beverages, beer had low amounts of the hydroxy acids. Nevertheless, the $3 \mathrm{OH} 3 \mathrm{MB}$ concentration in beer was among the highest values found in the whole set of samples. This is curious taking into account the scarce presence of this compound in the rest of the samples and could be due to the use of barley instead of grapes. To the best of the authors' knowledge, to date, this acid has only been quantified in honey samples [27]. In the distilled beverages, only $3 \mathrm{OHBc}$ was detected and the concentrations were low. This could be explained, taking into account the high polarity of these compounds that would hinder their volatilization during the distillation process.

In general, the concentrations of $2 \mathrm{OH} 4 \mathrm{MP}$ are lower in white than in red wines, as was already reported for its ethyl ester in the same kind of wines [13]. Although average values of 2OH4MP are higher in young than in aged red wines, the differences are not significant due to the huge range at which these compounds seem to be naturally present in wines.

\section{Conclusions}

A specific method has been developed to analyse five hydroxy acids present in wine and other beverages: $2 \mathrm{OH} 2 \mathrm{MB}, 3 \mathrm{OH} 3 \mathrm{MB}, 2 \mathrm{OH} 3 \mathrm{MB}, 2 \mathrm{OH} 4 \mathrm{MP}$ and $3 \mathrm{OHBc}$.

The first specific analysis of these hydroxy acids in a wide variety of wines and other alcoholic beverages has been done, showing interesting differences in concentration depending on the sample type.

The availability of the method presented enables further research to be carried out into the origin of the analytes and their capacity as precursors of the corresponding hydroxy esters.

\section{Acknowledgments}


The Spanish Government funded this work: project CICYT AGL2010-22355C02-01. E. Gracia-Moreno is grateful to the Spanish Government for support from the "Formación de Profesorado Universitario" (FPU) program (grant number: AP2008-03811). The authors acknowledge E. Franco Aladrén for providing the grape must derived alcoholic beverages produced in "Unidad de Enología del Gobierno de Aragón" and used in this experiment.

Conflict of interest The authors declare that they have no conflict of interest.

\section{Electronic supplementary material}

Below is the link to the electronic supplementary material.

\section{ESM 1}

(PDF $1761 \mathrm{~kb})$

\section{References}

1. Etievant PX (1991) In: Dekker MH (ed) Volatile compounds of food and beverages, New York, USA

2. Mirandalopez R, Libbey LM et al (1992) Identification of additional odor-active compounds in Pinot-Noir wines. Am J Enol Vitic 43(1):90-92

3. Peinado RA, Moreno J et al (2004) Changes in volatile compounds and aromatic series in sherry wine with high gluconic acid levels subjected to aging by submerged flor yeast cultures. Biotechnol Lett 26(9):757-762

4. Chaves M, Zea L et al (2007) Changes in color and odorant compounds during oxidative aging of Pedro Ximenez sweet wines. J Agric Food Chem 55(9):3592-3598

5. Pineau B, Barbe J-C et al (2009) Examples of perceptive interactions involved in specific "Red-" and "Black-berry" aromas in red wines. J Agric Food Chem 57(9):3702-3708 
6. Makhotkina O, Kilmartin PA (2012) Hydrolysis and formation of volatile esters in New Zealand Sauvignon blanc wine. Food Chem 135(2):486-493

7. Ramey DD, Ough CS (1980) Volatile ester hydrolysis or formation during storage of model solutions and wines. J Agric Food Chem 28(5):928-934

8. Diaz-Maroto MC, Schneider R et al (2005) Formation pathways of ethyl esters of branched short-chain fatty acids during wine aging. J Agric Food Chem 53(9):3503-3509

9. Campo E, Ferreira V et al (2006) Identification of three novel compounds in wine by means of a laboratory-constructed multidimensional gas chromatographic system. J Chromatogr A 1122(1-2):202-208

10. Campo E, Cacho J et al (2006) Multidimensional chromatographic approach applied to the identification of novel aroma compounds in wine Identification of ethyl cyclohexanoate, ethyl 2-hydroxy-3-methylbutyrate and ethyl 2-hydroxy-4-methylpentanoate. J Chromatogr A 1137(2):223230

11. Gracia-Moreno E, Lopez R et al (2015) Determination of 2-, 3-, 4methylpentanoic and cyclohexanecarboxylic acids in wine: development of a selective method based on solid phase extraction and gas chromatography-negative chemical ionization mass spectrometry and its application to different wines and alcoholic beverages. J Chromatogr A $1381: 210-218$

12. Falcao LD, Lytra $G$ et al (2012) Identification of ethyl 2-hydroxy-4methylpentanoate in red wines, a compound involved in blackberry aroma. Food Chem 132(1):230-236

13. Lytra G, Tempere S et al (2012) Distribution and organoleptic impact of ethyl 2-hydroxy-4-methylpentanoate enantiomers in wine. J Agric Food Chem 60(6):1503-1509 
14. Lytra G, Tempere $S$ et al (2012) Impact of perceptive interactions on red wine fruity aroma. J Agric Food Chem 60(50):12260-12269

15. Lytra G, Tempere $S$ et al (2013) Study of sensory interactions among red wine fruity esters in a model solution. J Agric Food Chem 61(36):8504-8513

16. Schreier P, Drawert F et al (1976) GLC-mass-spectrometrical investigation of volatile components of wines 6 . Aroma compounds of Tokaj-Aszu wines A) neutral compounds. Z Lebensm Unters Forsch 161(3):249-258

17. Umano K, Hagi Y et al (1992) Volatile constituents of green and ripened pineapple (Ananas comosus [L.] Merr.). J Agric Food Chem 40(4):599-603

18. Sampaio KL, Garruti DS et al (2011) Aroma volatiles recovered in the water phase of cashew apple (Anacardium occidentale L.) juice during concentration. J Sci Food Agric 91(10):1801-1809

19. Aurore G, Ginies C et al (2011) Comparative study of free and glycoconjugated volatile compounds of three banana cultivars from French West Indies: Cavendish, Frayssinette and Plantain. Food Chem 129(1):2834

20. Tiitinen K, Hakala M et al (2006) Headspace volatiles from frozen berries of sea buckthorn (Hippophae rhamnoides L.) varieties. Eur Food Res Technol 223(4):455-460

21. Umano K, Hagi Y et al (2002) Volatile chemicals identified in extracts from newly hybrid citrus, dekopon (Shiranuhi mandarin Suppl. J.). J Agric Food Chem 50(19):5355-5359

22. Kepner RE, Webb AD et al (1968) Sherry aroma.7. Some volatile components of flor Sherry of Spanish origin. Acidic compounds. Am J Enol Vitic 19(2):116-120 
23. Drawert F, Schreier P et al (1974) Glc-mass-spectrometrical investigation of volatile components of wines 3 . Acidic compounds of wine aroma. Z Lebensm Unters Forsch 155(6):342-347

24. Drawert F, Schreier P et al (1976) GLC-mass-spectrometrical investigation of the volatile components of wines vii. Aroma compounds of tokaj aszu wines b) organic acids (author's transl). Z Lebensm Unters Forsch 162(1):11-20

25. Meng J, Fang Y et al (2011) Changes in aromatic compounds of cabernet sauvignon wines during ageing in stainless steel tanks. Afr J Biotechnol 10(55):11640-11647

26. Gonzalez-Rodriguez J, Perez-Juan P et al (2003) Superheated liquids for extraction of solid residues from winemaking processes. Anal Bioanal Chem 377(7-8):1190-1195

27. Tan ST, Wilkins AL et al (1990) Extractive from New-Zealand honeys.3. Unifloral thyme and willow honey constituents. J Agric Food Chem 38(9):1833-1838

28. Abd El-Hady FK, Shaker KH (2013) Honey protects human low density lipoprotein (LDL) from peroxidation (in -vitro study). Int J Pharm Sci Rev Res 23(2):191-197

29. van der Wal B, Kettenes DK et al (1971) New volatile components of roasted cocoa. J Agric Food Chem 19(2):276-280

30. Wang L-J, Mu H-L et al (2010) Volatile components in three commercial Douchies, a Chinese traditional salt-fermented soybean food. Int J Food Prop 13(5):1117-1133

31. Temina M, Rezankova $\mathrm{H}$ et al (2007) Diversity of the fatty acids of the Nostoc species and their statistical analysis. Microbiol Res 162(4):308-321

32. Batovska DI, Todorova IT et al (2008) Preliminary study on 
biomarkers for the fungal resistance in Vitis vinifera leaves. J Plant Physiol 165(8):791-795

33. Batovska DI, Todorova IT et al (2009) Biomarkers for the prediction of the resistance and susceptibility of grapevine leaves to downy mildew. J Plant Physiol 166(7):781-785

34. Lopez R, Aznar M et al (2002) Determination of minor and trace volatile compounds in wine by solid-phase extraction and gas chromatography with mass spectrometric detection. J Chromatogr A 966(1-2):167-177

35. Gracia-Moreno E, Lopez R et al (2015) Determination of 2-, 3-, 4methylpentanoic and cyclohexanecarboxylic acids in wine: development of a selective method based on solid phase extraction and gas chromatography-negative chemical ionization mass spectrometry and its application to different wines and alcoholic beverages. J Chromatogr A(0)

36. Lu X, Cai JL et al (2003) Analysis of cigarette smoke condensates by comprehensive two-dimensional gas chromatography/time-of-flight mass spectrometry 1 acidic fraction. Anal Chem 75(17):4441-4451

37. Cullere L, Bueno M et al (2010) Selectivity and efficiency of different reversed-phase and mixed-mode sorbents to preconcentrate and isolate aroma molecules. J Chromatogr A 1217(10):1557-1566

38. Mateo-Vivaracho L, Cacho J et al (2007) Quantitative determination of wine polyfunctional mercaptans at nanogram per liter level by gas chromatography-negative ion mass spectrometric analysis of their pentafluorobenzyl derivatives. J Chromatogr A 1146(2):242-250

39. Zapata J, Mateo-Vivaracho L et al (2010) Comparison of extraction techniques and mass spectrometric ionization modes in the analysis of wine volatile carbonyls. Anal Chim Acta 660(1-2):197-205

40. Xia Q, Wu C et al (2014) Selection and application of potential wholecell enzymes in the esterification of Huangshui, a by-product formed 
during Chinese liquor-making. J Inst Brew 120(1):45-51

41. Bader J, Rauschenbach P et al (1982) On a hitherto unknown fermentation path of several amimo-acids by proteolytic clostridia. FEBS Lett 140(1):67-72

42. Khelifa N, Butel MJ et al (1998) Synthesis of 2-hydroxy acid from 2amino acid by Clostridium butyricum. Bioorg Med Chem Lett 8(23):34293434

43. Butel MJ, Rimbault A et al (1995) Formation of 2-hydroxy-4methylpentanoic acid from L-leucine by clostridium-butyricum. FEMS Microbiol Lett 132(1-2):171-176

44. Gracia-Moreno E (due 2015) Nuevos métodos analíticos para la determinación selectiva de pirazinas, ácidos y otros compuestos de interés aromático presentes en cantidades traza. (Title in English: New analytical methods for the selective determination of pyrazines, acids and other relevant aroma compounds present at traze levels). Universidad de Zaragoza (Spain), Language: English, In realization 